\title{
A Study to Evaluate the Significance of Sherren's Triangle Hyperaesthesia in a Treatment of Acute Appendicitis
}

\author{
Amarnath Gupta ${ }^{\oplus 1}$, Awdesh Prasad Singh ${ }^{\circ 2}$ \\ ${ }^{1}$ Senior Resident, Department of General Surgery, Government Medical College, Bettiah, Bihar, India, ${ }^{2}$ Professor \& HOD, Department of General Surgery, Government \\ Medical College, Bettiah, Bihar, India.
}

\section{Abstract}

Background: Acute appendicitis is the most common surgical emergency. In spite of sophisticated new investigations mainstay of diagnosis depends on clinical sign and symptoms, Sherren's triangle hyperaesthesia is very important sign with controversial efficacy about it in available literature. The aim of this study was to explore the significance of hyperaesthesia in Sherren's triangle in a treatment of acute appendicitis. Subjects and Methods: This study was conducted in 418 patients with 186 females and 251 males. Patients were of acute appendicitis operated for appendicectomy included in the study. Results: Sensitivity and specificity of hyperaesthesia in Sherren's triangle were $47.7 \%$ and $42.9 \%$ respectively with positive and negative predictive values were $92.1 \%$ and 5.56\%. Conclusion: Hence it indicates that hyperaesthesia in Sherren's triangle is important sign to suspect to support diagnosis of acute appendicitis. It has minimal significance to rule out it. This sign plays very important role in a diagnosis of complicated appendicitis like obstructive appendicitis.

Keywords: Appendicitis, Hyperaesthesia, Peritonitis

Corresponding Author: Amarnath Gupta, Senior Resident, Department of General Surgery, Government Medical College, Bettiah, Bihar, India. E-mail: amarpmch@gmail.com

Received: 18 December 2019

Revised: 24 January 2020

Accepted: 31 January 2020

Published: 26 May 2020

\section{Introduction}

The classical signs and symptoms of acute appendicitis were first time described by Reginald Haber Fitz in 1886. Since then it has remained the most common disease for hospital admission requiring surgery. Around $6 \%$ of the population will suffer from acute appendicitis during their lifetime; therefore, most research has been directed toward early diagnosis and intervention. This effort has successfully lowered the mortality rate to less than $0.1 \%$ for noncomplicated appendicitis, $0.6 \%$ where there is gangrene and $5 \%$ for perforated cases. The diagnosis of appendicitis can be difficult, occasionally taxing the diagnostic skills of even the experienced surgeon. Equivocal cases usually require inpatient observation. This delay in diagnosis may increase the morbidity and costs. Attempts to increase the diagnostic accuracy in acute appendicitis have included computer aided diagnosis, imaging by ultrasonography, laparoscopy and even radioactive isotope imaging. Various scoring systems have been devised to aid diagnosis. ${ }^{[1]}$ A clinical decision to operate leads to the removal of a normal appendix in $15 \%$ to $30 \%$ of cases. Reductions in the number of "unnecessary" operations should not, however, be achieved at the expense of an increase in the number of perforations. ${ }^{[2]}$

Acute appendicitis is the most common surgical emergency and the decision for appendicectomy is usually based on clinical signs and symptoms of acute appendicitis. Hyperaesthesia in Sherren's triangle is important sign which actually suggest presence of appendicitis. Although certain investigations such as C-reactive protein, ultrasonography and spiral CT scan abdomen lead to improved diagnosis. The gold-standard for diagnosis of acute appendicitis is histopathology. ${ }^{[1]}$ Appendectomy is the treatment of choice for acute appendicitis (AA) which has a morbidity of $3.1 \%$. With perforation, the morbidity is varied but can reach up to $47.2 \%$, while the mortality rate is less than $1 \%$. The high morbidity rate is due to a delay in presentation and initiation of active treatment, as well as patient factors. AA is a potential risk for patients due to the life- threatening complications. Therefore, careful assessment at emergency departments is mandatory to avoid preventable complications associated with AA. Observation has improved the ability to distinguish patients with appendicitis from those without, while negative explorations are related to improper assessments based mainly on the findings of the clinical examination rather than imaging studies, as well as the inflammatory 
marker status. ${ }^{[3]}$

Sherren's description of the appendix triangle, which is outlined by lines joining the summit of the iliac crest, the pubic tubercle, and the umbilicus, refers to an area of skin hyperaesthesia met with in obstructive appendicitis and indicates that the appendix is distended and may burst at any moment. This is a certain indication for immediate surgery. This observation was one of the outcomes of the research he had carried out with Sir Henry Head on the problem of cutaneous hypersensitivity in visceral disease. ${ }^{[4]}$

Out of all signs hyperaesthesia in Sherren's triangle is a very important sign suggesting presence of complication like peritonitis and immediate need of surgical intervention. Thus the aim of this study was to explore significance of hyperaesthesia in Sherren's triangle in a treatment of acute appendicitis.

\section{Subjects and Methods}

This prospective study was conducted at Government Medical College (GMC), Bettiah. The study was approved by the institutional research committee. A total of 437 patients (186 female and 251 male) who were admitted under the department of general surgery at GMC, Bettiah, from January 2017 to September 2019 were evaluated in this study. The clinical diagnosis and the decision of the appendectomy had been made by the surgeon who was not blinded to the preoperative imaging studies required in some patients. The inclusion criteria included all patients who were admitted with a diagnosis of AA (including complicated appendicitis) and also who underwent laparoscopic appendectomy, regardless of age, gender, all AA patients which refers to the inflammation of the appendix was evaluated by the surgeon macroscopically and confirmed on histopathological examination of the specimen. The diagnosis of AA and the decision to operate depends mainly on the clinical picture and investigations, such as white cell count, C- reactive protein level, abdominal and pelvic ultrasonography, and sometimes computed tomography (CT), especially in females of childbearing age and in borderline cases. Standard histological examination was conducted for all specimens. Sensitivity and specificity of hyperaesthesia in Sherren's triangle [Figure 1] was calculated using SPSS Software version 13.0.

\section{Results}

437 patients were admitted with the diagnosis of AA and underwent appendectomy. A total of 186 women and 251 men were included in this study. The mean age was 28.8 (range 18 - 63) years. [Graph 1]

\section{Graph 1: Distribution of Subjects}

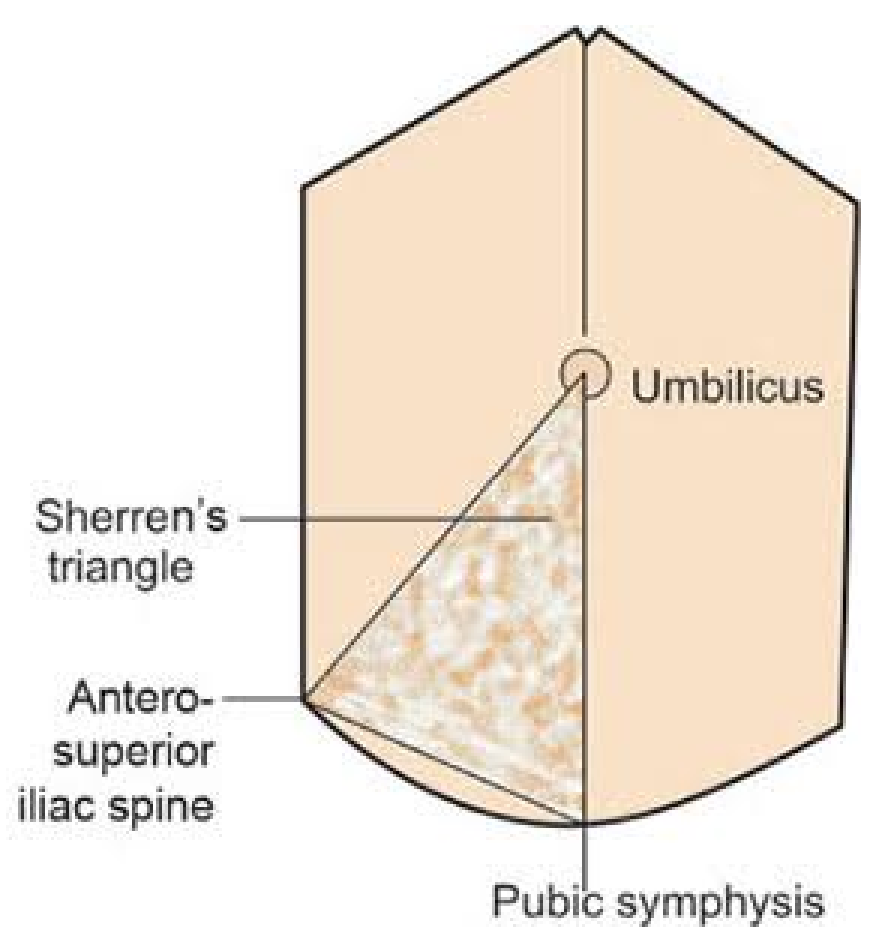

Figure 1: Sherren's triangle.

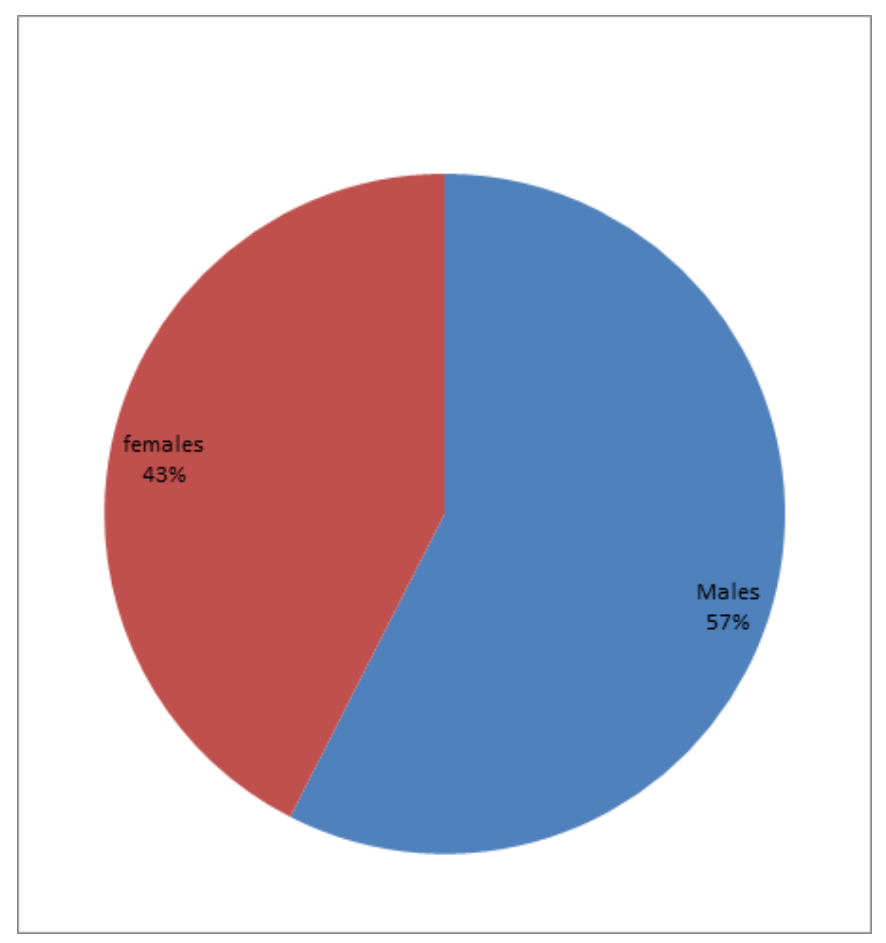

Figure 2: Gender Distribution 
Table 1: Sensitivity, specificity, PPV, NPV and accuracy of hyperaesthesia in sherren's triangle.

\begin{tabular}{llllll} 
Hyperaesthesia in sherren's triangle & Sensitivity & Specificity & PPV & NPV & Accuracy \\
& 47.7 & 42.9 & 92.1 & 5.56 & $47.37 \%$ \\
\hline
\end{tabular}

Normal appendix found in 50 cases, hence negative appendicectomy rate was $11.96 \%$. Different pathology was found in 1 in the form of carcinoid of appendix $(0.24 \%)$ but treated by appendicectomy. Sensitivity of hyperaesthesia in Sherren's triangle was $47.7 \%$ and specificity was $42.7 \%$, positive predictive value and negative predictive values were $92.1 \%$ and $5.56 \%$ [Table 1] respectively to diagnose acute appendicitis.

There were 13 cases of appendicular perforation observed in this study out of $418(3.11 \%), 8(1.19 \%)$ were females and $5(1.19 \%)$ were males, out of 13 only 1 patient was having no Hyperesthesia in Sherren's triangle rest in all 12 patients it was elicited.

Only in 70 cases this sign was elicited out of $418(16.74 \%)$ in the study, 40 were females and 30 were males.

\section{Discussion}

437 patients were admitted with the diagnosis of AA and underwent appendectomy. A total of 186 women and 251 men were included in this study. The mean age was 28.8 (range 18 - 63) years. Different pathology was found in 1 in the form of carcinoid of appendix $(0.24 \%)$ but treated by appendicectomy.

Sherren's triangle hyperaesthesia is area of skin hyperaesthesia bounded by lines joining anterior superior iliac spine, the pubic symphysis and umbilicus. It was described by the English surgeon James Sherren. Hyperesthesia in Sherren's triangle was the first parameter included to broaden the diagnostic kit by Yash et al. ${ }^{[5]}$ This sign was having good sensitivity (47.69\%) and PPV (92.08\%). They offered score of 1 in Yash scoring system as per its probability and odd's ratio, in their study positive and negative predictive value of modified Alvarado score (mass) were $13.02 \%$ and $100 \%$ respectively. Diagnostic accuracy was $55.26 \%$. Same results observed from a study done by Lone included 240 patients, 138 males and 102 females. ${ }^{[6]}$ Alvarado score works well in men with more than seven score. However, high negative appendectomy rates are observed in females even with a score exceding seven. Over all Negative appendicectomy rate was $17 \%$.and in female it was $20 \%$. ${ }^{[6]}$

The Yash score was having sensitivity of $99.48 \%$ and specificity of $92.86 \%$ with positive predictive value and negative predictive value of $99.48 \%$ and $92.85 \%$ respectively. Diagnostic accuracy was $98.56 \%$. Cut point of 7 gives highest sensitivity and specificity of $96.67 \%$ and $100.00 \%$ respectively. Comparison in-between YSS and MASS shows superior results of YSS. Actually, speaking YSS was a modification of MASS with addition of three more parameters (Hyperesthesia in Sherren's triangle, C-reactive protein and ultrasonography).

Though this sign was elicited in only 70 patients out of 418 patients in present study which reflected its lower sensitivity and low positive predictive value. But its power to diagnose complicated appendicitis like perforation and obstructive appendicitis cannot be neglected. In an era of antibiotics in a study done by Salminen et al among patients with computerized tomography $(\mathrm{CT})$ proven uncomplicated appendicitis, antibiotic treatment was as effective as appendectomy. ${ }^{[7]}$ Most patients randomized to antibiotic treatment for uncomplicated appendicitis did not require appendectomy during the 1year follow-up period, and those who required appendectomy did not experience significant complications. Here by offering non-operative treatment to the patient of uncomplicated acute appendicitis is revolutionary, but with difficult task to diagnose uncomplicated acute appendicitis correctly. In most of the studies computerized tomography is used as tool to rule out complicated AA.

Though CT was proven most accurate tool to diagnose complicated appendicitis in most of the studies, but few studies still denies its efficacy like study done by Khairy et al reveals that a normal appendix was removed in $54(9.2 \%)$ patients, 39 women (72\%) and 15 men (28\%). ${ }^{[8,9]}$ 9,10 Even after using CT scan and laparoscopy in atypical cases. So, he draws inference that the routine uses of CT scan or diagnostic laparoscopy for all patients who are suspected to have appendicitis is neither cost-effective nor safe.

This confusion regarding efficacy of CT needs some enforcement in relation with management of uncomplicated appendicitis by antibiotcs. ${ }^{[10]}$ This investigation (CT) can be effectively strengthened by the use of Hyperesthesia in Sherren's triangle. This signifies importance of it in a diagnosis of complicated AA.

\section{Conclusion}

In contradiction to some previously published reports, this study emphasizes the role of Hyperesthesia in Sherren's triangle in the clinical diagnosis of acute appendicitis. Sensitivity and specificity of this sign towards appendicular perforation were $92 \%$ and $43 \%$ respectively, the positive and negative predictive (NPV) value were 5\% and $99 \%$ respectively. It suggests this sign plays very important role in a diagnosis of complicated appendicitis like obstructive 
appendicitis.

\section{References}

1. Al-Hashemy AM, Seleem MI. Appraisal of the modified Alvarado Score for acute appendicits in adults. Saudi Med J. 2004;25(9):1229-1260.

2. Ibrahim M, Sak M, Kreshnan TR, Sharma R, Abdel-Shaheed AA, Habib MA. Ultrasonography in the diagnosis of clinically equivocal acute appendicitis: a prospective study. Kuwait Med J. 2003;35(3):271-275.

3. Hussain A, Mahmood H, Singhal T, Balakrishnan S, ElHasani S. What is positive appendicitis? A new answer to an old question. Clinical, macroscopical and microscopical findings in 200 consecutive appendectomies. Singapore Med J. 2009;50(12):1145-1145.

4. Moore AM, Moore MA. James Sherren-surgeon and sailor. Br J Surg. 1973;60(11):841-846. Available from: https://dx.doi.org/10.1002/bjs.1800601102. doi:10.1002/bjs.1800601102.

5. Lamture YR, Ramteke H, Shinde RK, Shahapurkar VV, Gajbhiye VP. Clinico sonological and laboratory corelation with histopathology of acute appendicitis to develop new diagnostic scoring system (Yash scoring system). Int Surg J. 2017;4(8):2556-2556. Available from: https://dx.doi.org/10.18203/2349-2902.isj20173211. doi:10.18203/2349-2902.isj20173211.

6. Lone NA, Shah M, Wani KA, Peer GQ. Modified Alvarado Score in Diagnosis of Acute Appendicitis. Indian J Practi Doc. 2006;3(2).

7. Salminen P, Paajanen H, Rautio T, Nordström P, Aarnio M, Rantanen T, et al. Antibiotic Therapy vs Appendectomy for
Treatment of Uncomplicated Acute Appendicitis. JAMA. 2015;313(23):2340-2340. Available from: https://dx.doi.org/ 10.1001/jama.2015.6154. doi:10.1001/jama.2015.6154.

8. A M, N B. Acute appendicitis dilemma of diagnosis and management. Internet J Surg. 2010;23(1):18-22.

9. Khairy G. Acute appendicitis: Is removal of a normal appendix still existing and can we reduce its rate? Saudi J Gastroenterol. 2009;15(3):167-167. Available from: https://dx.doi.org/10. 4103/1319-3767.51367. doi:10.4103/1319-3767.51367.

10. Varadhan KK, Neal KR, Lobo DN. Safety and efficacy of antibiotics compared with appendicectomy for treatment of uncomplicated acute appendicitis: meta-analysis of randomised controlled trials. $\mathrm{Br}$ Med J. 2012;344:e2156e2156. Available from: https://dx.doi.org/10.1136/bmj.e2156. doi:10.1136/bmj.e2156.

Copyright: (C) the author(s), 2020. It is an open-access article distributed under the terms of the Creative Commons Attribution License (CC BY 4.0), which permits authors to retain ownership of the copyright for their content, and allow anyone to download, reuse, reprint, modify, distribute and/or copy the content as long as the original authors and source are cited.

How to cite this article: Gupta A, Singh AP. A Study to Evaluate the Significance of Sherren's Triangle Hyperaesthesia in a Treatment of Acute Appendicitis. Acad. J Surg. 2020;3(1): 12-15.

DOI: dx.doi.org/10.47008/ajs/2020.3.1.3

Source of Support: Nil, Conflict of Interest: None declared. 